\title{
Extracellular Water-to-total Body Water Ratio as an Objective Biomarker for Frailty in Lung Cancer Patients
}

\author{
TOMONORI HIRASHIMA ${ }^{1}$, YOSHIMI NODA ${ }^{1,2}$, HIDEKAZU SUZUKI $^{1}$, SHINGO NASU $^{1}$, AYAKO TANAKA $^{1}$, \\ NAOKO MORISHITA $^{1}$, NORIKO RYOTA ${ }^{3}$, KAORI IWATA $^{3}$, YUKARI OKADA ${ }^{3}$ and NORIO OKAMOTO ${ }^{1}$ \\ ${ }^{1}$ Department of Thoracic Oncology, Osaka Habikino Medical Center, Osaka, Japan; \\ ${ }^{2}$ Department of Respiratory Medicine and Clinical Immunology, \\ Graduate School of Medicine, Osaka University, Osaka, Japan; \\ ${ }^{3}$ Department of Nursing, Osaka Habikino Medical Center, Osaka, Japan
}

\begin{abstract}
Background/Aim: Our previous study revealed the association between extracellular water-to-total body water ratio $(E C W / T B W)$ and the therapeutic durability of chemotherapy and/or immune checkpoint inhibitors in advanced lung cancer. We retrospectively examined the usefulness of ECW/TBW in detecting frailty compared to other bioelectrical impedance (BIA) parameters in a larger number of patients. Patients and Methods: Lung cancer patients underwent BIA before anti-cancer therapy at our hospital between June 1, 2018 and July 31, 2020. Results: Of 99 patients, 26 were assigned to $E C W / T B W \geq 0.4$ (higher group: $H G$ ) and 57 to $E C W / T B W<0.4$ (lower group: $L G$ ). $E C W / T B W$ increased significantly with performance deterioration and ageing. $H G$ patients had significantly shorter time-to-treatment failure (TTF) than LG patients. In patients with performance status $0-1$, those in the $H G$ had shorter TTF than those in the LG. ECW/TBW was the only independent predictor of TTF according to multivariate analysis. Conclusion: ECW/TBW is an objective biomarker for detecting frailty among lung cancer patients.
\end{abstract}

In Japan, the number of elderly patients with lung cancer (LC) is increasing (1) and as of $2017,49.2 \%$ of Japanese patients are diagnosed with LC at the age of $\geq 75$ years (1). Among cancer patients, particularly the elderly, it is

This article is freely accessible online.

Correspondence to: Tomonori Hirashima, MD, Department of Thoracic Oncology, Osaka Habikino Medical Center, 3-7-1 Habikino, Habikino City, Osaka 583-8588, Japan. Tel: +81 729572121, Fax: +81 729578002, e-mail: hirashimat@ra.opho.jp

Key Words: Lung cancer, bioelectrical impedance analysis, ratio of extracellular water to total body water, time to treatment failure, frailty. important to determine whether the patient would be fit, unfit, vulnerable, or frail for cancer treatment; however, this is often difficult.

In a review article (2), Ethun et al. reported that the concept of frailty is increasingly recognized as one of the most important issues in healthcare and health outcomes, and it is of particular importance among cancer patients undergoing surgery, chemotherapy, and radiotherapy; nevertheless, as the review article mentioned, detecting frailty can be challenging.

In our previous study (3), we reported that extracellular water (ECW)-to-total body water (TBW) ratio (ECW/TBW) measured by bioelectrical impedance (BIA) was an objective parameter for predicting therapeutic durability in patients with LC. Similarly, ECW/TBW is reportedly useful in evaluating the general condition of patients with liver cirrhosis (4), renal failure (5), and heart failure (6).

In this study, we retrospectively examined the usefulness of ECW/TBW in detecting frailty compared to other BIA parameters and in a larger number of patients than our previous study (3).

\section{Patients and Methods}

Ethical statements. This retrospective study's protocol was approved by the institutional review board of the Osaka Habikino Medical Center on December 28, 2020 (approval number: 1063). All research was conducted in accordance with the 1964 Declaration of Helsinki and its later amendments. The requirement for informed consent was waived based on the retrospective design and the anonymization of the data. This study was also performed in accordance with our centre's opt-out policy.

Patient selection. We selected 99 LC patients who underwent BIA before receiving anti-cancer therapy at our institution between June 1,2018 , and July 31,2020 , as follows: 75 patients were included in our previous study (3) and 24 patients were newly included in this study. The patients enrolled in the prospective observational study (UMIN000037451) were excluded from this study. 
BIA testing and parameters. A multi-frequency (MF)-BIA scanner (InBody770; InBody, Seoul, Korea) was used within 2 weeks prior to cancer treatment to collect data regarding TBW, ECW, intracellular water (ICW), protein, mineral, and fat-free mass (FFM). Segmental resistances were measured using eight surface electrodes at the thumb, fingers, ball of the foot, and heel, while the patient kept both arms abducted from the mid-body. Microprocessor-controlled switches and an impedance analyser were activated in the sensors to measure segmental resistance at six frequencies $(1 \mathrm{kHz}, 5 \mathrm{kHz}, 50 \mathrm{kHz}, 250 \mathrm{kHz}, 500 \mathrm{kHz}$, and 1,000 $\mathrm{kHz}$ ). The measurements were performed in two combinations: resistance in the z-axis at frequencies of $1 \mathrm{kHz}, 5 \mathrm{kHz}, 50 \mathrm{kHz}, 250$ $\mathrm{kHz}, 500 \mathrm{kHz}$, and $1000 \mathrm{kHz}$, and reactance in the $\mathrm{x}$-axis at frequencies of $5 \mathrm{kHz}, 50 \mathrm{kHz}$, and $250 \mathrm{kHz}$.

The MF-BIA estimated TBW based on the impedance value when the electric current flowed through the water in the body. The phase angle $(\mathrm{Ph}-\mathrm{A})$ value was calculated using resistance $(\mathrm{R})$ and reactance $(\mathrm{Xc}$; measured at $50 \mathrm{kHz}$ ) through the following equation: $\mathrm{Ph}-\mathrm{A}\left({ }^{\circ}\right)=\operatorname{arctangent}(\mathrm{Xc} / \mathrm{R}) \times(180 / \pi)(7)$. The ECW and ICW values were estimated based on the balance between the highfrequency current travelling through the TBW and the lowfrequency current travelling through the ECW. The ECW/TBW was calculated based on previously reported principles (8). Protein and FFM values were calculated based on the estimated ICW and TBW values, respectively. Mineral and osseous mineral values were calculated based on the estimated FFM value. The lean body mass and skeletal muscle mass were calculated based on the FFM and osseous mineral values, respectively. Muscle volume was calculated based on the methods described in a previous study (9).

Body composition parameters. Body mass index (BMI, $\mathrm{kg} / \mathrm{m}^{2}$ ) values were calculated as weight divided by height squared $\left(\mathrm{kg} / \mathrm{m}^{2}\right)$. In this study, the BMI was calculated using the BIA scanner device along with the other parameters, and it was included as a BIA parameter. The other BIA parameters were defined as the fat-free mass index (FFMI; $\mathrm{kg} / \mathrm{m}^{2}$ ), the skeletal muscle mass index (SMI; $\left.\mathrm{kg} / \mathrm{m}^{2}\right), \mathrm{ECW} / \mathrm{TBW}$, and $\mathrm{Ph}-\mathrm{A}\left({ }^{\circ}\right)$. The FFMI values were calculated as FFM divided by height squared $\left(\mathrm{kg} / \mathrm{m}^{2}\right)$.

Clinical and laboratory parameters. Patient clinical records were reviewed to collect baseline data regarding age, sex, Eastern Cooperative Oncology Group performance status (ECOG PS 0/1/2/3), histology (adenocarcinoma/squamous cell carcinoma/small cell lung cancer/others), disease stage (II-III/IV/recurrence), smoking status (never/former/current), and previous treatments $(0 / \geq 1)$. Comorbidity in this study was defined as the diseases required systemic medication or important diseases other than LC. Laboratory data were collected, including C-reactive protein (CRP, $\mathrm{mg} / \mathrm{dl})$, albumin $(\mathrm{g} / \mathrm{dl})$, and the neutrophil-to-lymphocyte ratio (NLR), within 7 days before and after the MF-BIA was performed.

Cut-off values for age, laboratory data, and BIA parameters. The age cut-off value was set at 75 years, which is conventionally defined as late-elderly. In contrast, the cut-off value for laboratory data was defined as the median value: high laboratory data was above the median value or higher. Finally, the cut-off values for the BIA parameters were as follows: low BMI value as $<20.0 \mathrm{~kg} / \mathrm{m}^{2}$ for patients $<70$ years old or $<22.0 \mathrm{~kg} / \mathrm{m}^{2}$ for patients $>70$ years old, according to the new European Society of Clinical Nutrition and Metabolism definition (10); low FFMI value as $<17 \mathrm{~kg} / \mathrm{m}^{2}$ for males and $<15 \mathrm{~kg} / \mathrm{m}^{2}$ for females, according to the same definition (10); low SMI value as $<7.0 \mathrm{~kg} / \mathrm{m}^{2}$ for males and $<5.7 \mathrm{~kg} / \mathrm{m}^{2}$ for females, according to the Asian consensus report (11); fluid overload as an $\mathrm{ECW} / \mathrm{TBW}$ value of $\geq 0.4$ (12); and high $\mathrm{Ph}-\mathrm{A}$ value as being above the median $\mathrm{Ph}-\mathrm{A}$ value.

Clinical outcomes. Time to treatment failure (TTF) was defined as the time between the start date of cancer treatment to the date of discontinuation for any reason, including progressive disease, adverse events, patient's refusal, and death. Disease progression was determined by diagnostic imaging, including computed tomography (CT), magnetic resonance imaging, bone scintigraphy, and positron emission tomography, according to the Response Evaluation Criteria in Solid Tumors (RECIST) guidelines version 1.1. The time of disease progression was considered as the day on which the CT was conducted. TTF data were last updated on December 14, 2020.

The degree of adverse events after cancer treatment was indicated using the grade $(\mathrm{G})$ notation of the Common Terminology Criteria for Adverse Events (CTCAE) version 5.0.

Statistical analyses. Inter-group differences were evaluated using the Chi-squared test or the Mann-Whitney $U$-test. The Kaplan-Meier method and log-rank test were used to compare the TTF curves. Furthermore, a Cox proportional hazards model was used to evaluate these outcomes, with the results reported as the hazard ratio (HR) and 95\% confidence interval (CI). Differences were considered statistically significant at $p$-values of $<0.05$. All statistical analyses were performed using R software (version 3.3.2) (13).

\section{Results}

Correlations between ECW/TBW and patient characteristics. This study included 99 LC patients, and their baseline characteristics are shown in Table I. Of these, 73 (73.7\%) were assigned into the group of ECW/TBW $<0.4$ (LG: lower group) and $26(26.3 \%)$ were assigned into the group of ECW/TBW $\geq 0.4$ (HG: higher group). Never-smoking status was significantly more frequently observed in HG $(12 / 26$ : 46.2\%) than LG (16/73: $21.9 \%)(p=0.018)$. The frequency (11/26: $42.3 \%)$ of patients with ECOG PS 2-3 in HG was significantly higher than that in LG $(8 / 73: 11.0 \%)(p=0.001)$. Aside from smoking status and ECOG PS, there were no significant differences between the two groups in terms of the other patient characteristics.

Correlations between ECW/TBW and other BIA parameters or laboratory data. As shown in Table II, the frequency of low BMI (20/26: $76.9 \%$ and 20/26: 76.9\%) and low SMI (31/73: $42.5 \%$ and 36/73: $49.3 \%$ ) in HG were significantly higher than those in LG $(p=0.005$ and $p=0.027$, respectively). The frequency of median $\mathrm{PH}-\mathrm{A} 4.3^{\circ}$ or lower in HG $(25 / 26: 96.2 \%)$ was significantly higher than that (28/73: $38.4 \%)$ in LG $(p<0.001)$.

Moreover, the frequency with albumin $<4.0$ (17/22: $77.3 \%)$ in HG was significantly higher than that (26/67: $38.8 \%)$ in LG $(p=0.004)$. However, serum albumin levels were not examined in 10 patients, including 6 in LG and 4 in HG. 
Table I. Patient characteristics.

\begin{tabular}{|c|c|c|c|c|}
\hline & \multirow{3}{*}{$\begin{array}{l}\text { All patients } \\
\qquad \mathrm{N}=99\end{array}$} & \multicolumn{2}{|c|}{ Extracellular water-to-total body water ratio } & \multirow[b]{3}{*}{$p$-Value } \\
\hline & & $<0.4(73.7 \%)$ & $\geq 0.4(26.3 \%)$ & \\
\hline & & $\mathrm{N}=73$ & $\mathrm{~N}=26$ & \\
\hline \multicolumn{5}{|l|}{ Clinical characteristics } \\
\hline \multicolumn{5}{|l|}{ Gender } \\
\hline Male & 66 & 51 & 15 & \multirow[t]{2}{*}{0.258} \\
\hline Female & 33 & 22 & 11 & \\
\hline \multicolumn{5}{|l|}{ Age (years old) } \\
\hline$<75$ & 54 & 44 & 10 & \multirow[t]{2}{*}{0.055} \\
\hline$\geq 75$ & 45 & 29 & 16 & \\
\hline \multicolumn{5}{|l|}{ Smoking status } \\
\hline Ever (Current/former) & $71(24 / 47)$ & $57(19 / 38)$ & $14(5 / 9)$ & \multirow[t]{2}{*}{0.018} \\
\hline Never & 28 & 16 & 12 & \\
\hline \multicolumn{5}{|l|}{ ECOG Performance status } \\
\hline $0-1(0 / 1)$ & $80(19 / 61)$ & $65(17 / 48)$ & $15(2 / 13)$ & \multirow[t]{2}{*}{0.001} \\
\hline $2-3(2 / 3)$ & $19(18 / 1)$ & $8(8 / 0)$ & $11(10 / 1)$ & \\
\hline \multicolumn{5}{|l|}{ Histology } \\
\hline Non-small cell carcinoma & 86 & 62 & 24 & \multirow[t]{2}{*}{0.565} \\
\hline Small cell carcinoma & 13 & 11 & 2 & \\
\hline \multicolumn{5}{|l|}{ Stage } \\
\hline II-III & 22 & 15 & 7 & \multirow[t]{2}{*}{0.692} \\
\hline Stage IV/Recurrence & $77(46 / 31)$ & $58(31 / 27)$ & $19(15 / 4)$ & \\
\hline \multicolumn{5}{|l|}{ Driver mutation } \\
\hline Yes & 20 & 13 & 7 & \multirow[t]{3}{*}{0.440} \\
\hline No & 73 & 56 & 17 & \\
\hline Not examined & 6 & 4 & 2 & \\
\hline \multicolumn{5}{|l|}{ Comorbidity } \\
\hline 0 & 38 & 31 & 7 & \multirow[t]{2}{*}{0.244} \\
\hline$\geq 1$ & 61 & 42 & 19 & \\
\hline \multicolumn{5}{|l|}{ Previous treatment line } \\
\hline 0 & 63 & 47 & 16 & \multirow[t]{2}{*}{0.796} \\
\hline$>1$ & 36 & 26 & 10 & \\
\hline \multicolumn{5}{|l|}{ Regimens } \\
\hline Cytotoxic chemotherapy & 51 & 34 & 17 & \multirow[t]{5}{*}{0.156} \\
\hline ICI monotherapy & 20 & 17 & 3 & \\
\hline ICI+ Cytotoxic chemotherapy & 6 & 6 & 0 & \\
\hline Chemoradiation therapy & 9 & 8 & 1 & \\
\hline Targeted therapy & 13 & 8 & 5 & \\
\hline
\end{tabular}

ECOG: Eastern Cooperative Oncology Group; ICI: immune checkpoint inhibitors.

Correlation between PS and BIA parameters. As shown in Figure 1, the ECW/TBW in patients with PS 0 [median (range): 0.389 (0.374-0.405)] was significantly lower than that in patients with PS 1 and PS 2-3 [0.394 (0.376-0.413) and $0.401(0.387-0.413)$; $(p=0.006$ and $p=0.001)$, respectively]. Moreover, the ECW/TBW in patients with PS 1 was significantly lower than that in patients with PS 2-3 ( $p=0.014)$. On the other hand, the Ph-A in patients with PS 0 [5.0 (3.46.4)] was significantly higher than that in patients with PS 1 and PS 2-3 [4.2 (2.7-6.3) and 3.8 (2.4-5.0); $(p=0.002$ and $p<0.001)$, respectively]. The $\mathrm{Ph}-\mathrm{A}$ in patients with PS 1 was also significantly higher than that in patients with PS 2-3 $(p=0.049)$. Finally, the BMI in patients with PS 0 [21.6 (16.0-
28.6)] was significantly higher than that in patients with PS 23 [20.1 (15.0-26.9)] $(p=0.034)$. However, there was no significant correlation between PS and SMI or FFMI.

Correlation between age and BIA parameters. As shown in Figure 2, the ECW/TBW in patients $<75$ years old [median (range): $0.392(0.374-0.416)]$ was significantly lower than that in patients $\geq 75$ years old $[0.397(0.381-0.418)](p=0.027)$. Nevertheless, there was no significant correlation between age and the other BIA parameters aside from ECW/TBW.

Reasons for treatment failure. Of the 99 patients in this study, 12 continued the regimen, 10 completed the treatment, 
Table II. Correlations between ECW/TBW and other BIA parameters or laboratory data.

\begin{tabular}{|c|c|c|c|c|}
\hline & \multirow{3}{*}{$\begin{array}{l}\text { All patients } \\
\qquad \mathrm{N}=99\end{array}$} & \multicolumn{2}{|c|}{$\mathrm{ECW} / \mathrm{TBW}$} & \multirow[b]{3}{*}{$p$-Value } \\
\hline & & $<0.4(73.7 \%)$ & $\geq 0.4(26.3 \%)$ & \\
\hline & & $\mathrm{N}=73$ & $\mathrm{~N}=26$ & \\
\hline \multicolumn{5}{|c|}{ Bioelectrical impedance } \\
\hline \multicolumn{5}{|c|}{ Body mass index $\left(\mathrm{kg} / \mathrm{m}^{2}\right)$} \\
\hline Low & 51 & 31 & 20 & \multirow[t]{2}{*}{0.005} \\
\hline Not low & 48 & 42 & 6 & \\
\hline \multicolumn{5}{|c|}{ Skelton muscle mass index $\left(\mathrm{kg} / \mathrm{m}^{2}\right)$} \\
\hline Low & 56 & 36 & 20 & \multirow[t]{2}{*}{0.027} \\
\hline Not low & 43 & 37 & 6 & \\
\hline \multicolumn{5}{|c|}{ Fat-free mass index $\left(\mathrm{kg} / \mathrm{m}^{2}\right)$} \\
\hline Low & 65 & 44 & 21 & \multirow[t]{2}{*}{0.099} \\
\hline Not low & 34 & 29 & 5 & \\
\hline \multicolumn{5}{|l|}{ Phase angle $\left({ }^{\circ}\right)$} \\
\hline$\leq 4.3$ & 53 & 28 & 25 & \multirow[t]{2}{*}{$<0.001$} \\
\hline$>4.3$ & 46 & 45 & 1 & \\
\hline \multicolumn{5}{|c|}{ Laboratory findings } \\
\hline \multicolumn{5}{|c|}{ C-reactive protein $(\mathrm{mg} / \mathrm{dl})$} \\
\hline$<0.3$ & 48 & 38 & 10 & \multirow[t]{2}{*}{0.234} \\
\hline$\geq 0.3$ & 51 & 35 & 16 & \\
\hline \multicolumn{5}{|l|}{ Albumin $(\mathrm{g} / \mathrm{dl})$} \\
\hline$<4.0$ & 43 & 26 & 17 & \multirow[t]{3}{*}{0.004} \\
\hline$\geq 4.0$ & 46 & 41 & 5 & \\
\hline Not examined & 10 & 6 & 4 & \\
\hline \multicolumn{5}{|c|}{ Ratio of neutrophil to lymphocyte } \\
\hline$<3.1$ & 49 & 40 & 9 & \multirow[t]{2}{*}{0.124} \\
\hline$\geq 3.1$ & 50 & 33 & 17 & \\
\hline
\end{tabular}

ECW/TBW: Extracellular water-to-total body water ratio.

and 77 discontinued the treatment due to the following reasons: disease progression, 50; adverse events, 22; symptom worsening, 4; and self-interruption of treatment, 1 . The details of the adverse events were as follows: 10 patients with interstitial pneumonitis $\mathrm{G} 1 / 2 / 3 / 4,3 / 1 / 5 / 1 ; 2$ with renal dysfunction $\mathrm{G} 1 / 2,1 / 1$; 2 with anaphylaxis $G 3,2$; each one patient with G3 oedema, G3 respiratory failure, G2 immunerelated colitis, G3 lung aspergillosis, G3 eruption, G2 whitlow, G3 bacterial pneumonia, and G3 immune-related myositis.

Correlation between TTF and patient characteristics or BIA parameters. As shown in Table III, the univariate analyses revealed that sex, ECOG PS, driver mutation, previous treatment line, ECW/TBW, and serum albumin were significantly correlated with TTF $(p=0.043,0.027,0.019$, $0.037,0.027$, and 0.007 , respectively). However, serum albumin and driver mutation were excluded from the multivariate analyses due to missing data. The results of the multivariate analyses are shown in Table III. They revealed that the only independent predictor of TTF was the $\mathrm{ECW} / \mathrm{TBW}(\mathrm{HR}=1.8,95 \% \mathrm{CI}=1.03-3.14, p=0.045)$.
As shown in Figure 3A, the patients in $\mathrm{HG}$ had significantly shorter median TTF (days) than those in LG (140 vs. 94, $\mathrm{HR}=1.74,95 \% \mathrm{CI}=1.06-2.83 ; p=0.027)$. Furthermore, as shown in Figure $3 \mathrm{~B}$, even in patients with PS $0-1$, those in $\mathrm{HG}$ tended to have shorter median TTF (days) compared to those in LG (146 vs. 63, HR=1.64, $95 \% \mathrm{CI}=0.887-3.030 ; p=0.111)$.

\section{Discussion}

This study showed that among the BIA parameters, ECW/TBW was the most strongly correlated with worsening PS and ageing in LC patients. Furthermore, this study reconfirmed that patients in $\mathrm{HG}$ had significantly shorter TTF than those in LG, similar to the previous study (3). Even in patients with PS $0-1$, those in HG tended to have shorter TTF. Although various tools for detecting frail populations among cancer patients are being examined, there is no standard tool yet (14). Therefore, ECW/TBW can be an objective biomarker for detecting potentially frail patients.

Morley et al. (15) reported an expert's consensus that frailty is a clinical syndrome characterised by increased vulnerability 

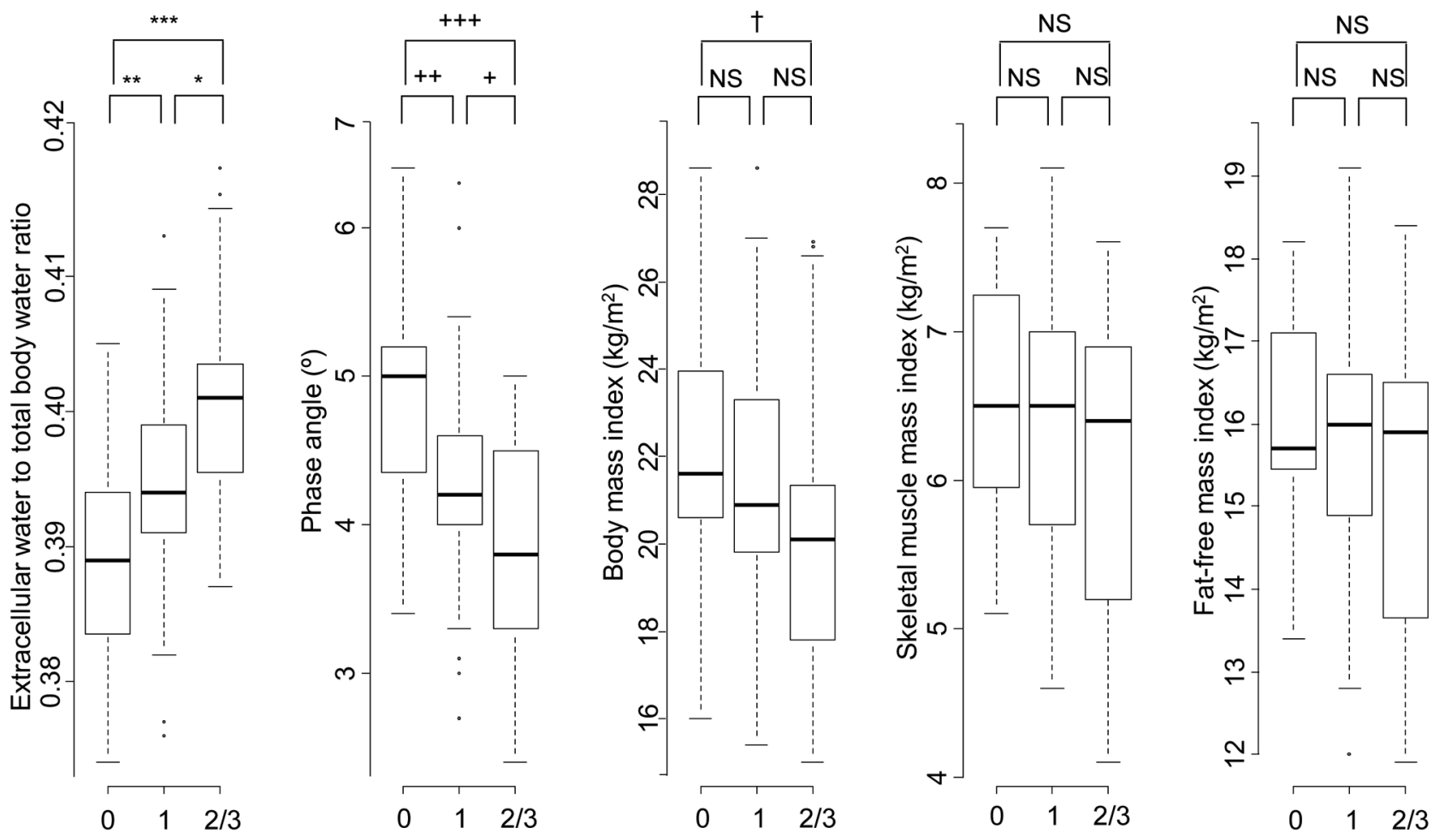

\section{Performance status}

Figure 1. Relationships between the bioelectrical impedance parameters and performance status. The extracellular water-to-total body water ratio $(E C W / T B W)$ increased with performance status $(P S)(* * 0$ vs. $1: p=0.006 ; * 1$ vs. $2: p=0.014 ; * * * 0$ vs. 2-3: $p=0.001)$. Phase angle $(P h-A)$ decreased with increasing PS values $\left({ }^{++} 0\right.$ vs. $1: p=0.002 ;{ }^{+} 1$ vs. 2-3: $p=0.049 ;{ }^{++} 0$ vs. $\left.2-3: p<0.001\right)$. Body mass index decreased with increasing $P S$ values $\left({ }^{\dagger} 0\right.$ vs. 2-3: $\left.p=0.034\right)$. The other bioelectrical impedance analysis (BIA) parameters were not correlated with PS.

and diminished resistance to stressors that can cause functional impairment and increase risks. BIA is a simple and non-invasive tool that can be used to assess frailty, including sarcopenia (11, 16), malnutrition, and cancer cachexia $(17,18)$. A recent review (19) reported that BIA is an accurate method for detecting sarcopenia in adults with cancer prior to treatment and is a viable alternative to $\mathrm{CT}$, dual-energy X-ray absorptiometry, and magnetic resonance imaging in oncology clinical practice. In the review, all articles defined sarcopenia using SMI or FFMI, as measured by BIA. However, the present study suggested that the important parameters in BIA would not be SMI or FFMI, which are secondarily calculated based on electric current, resistance, and reactance, but rather $\mathrm{ECW} / \mathrm{TBW}$, which is directly calculated. Several reports $(20,21)$ have also indicated that FFM measured by BIA would not be appropriate parameters for detecting the frail population among cancer patients, which might be related to the effect of body fluid retention on muscle mass estimation via altered impedance. Furthermore, this study indicated that ECW/TBW would more accurately detect the frail population among LC patients with potentially poor $\mathrm{PS}$ and/or ageing than $\mathrm{Ph}-\mathrm{A}$, directly calculated based on electric current, resistance, and reactance.

Nevertheless, the present study has several limitations that must be considered. First, this study had a retrospective single-centre design. Second, this study had inconsistencies in stage and histology, and the various treatment lines and regimens could introduce a risk of bias. Third, as a study of highly heterogeneous populations, the relatively small sample size may also be a source of bias. Finally, most patients included in this study did not perform cardiac function tests, such as echocardiography, although they may be overhydrated. In conclusion, ECW/TBW would be an objective biomarker for detecting frailty among lung cancer patients.

\section{Conflicts of Interest}

T.H. received honoraria and research funding as a primary investigator at this institution from Ono Pharmaceutical Co. Ltd. 

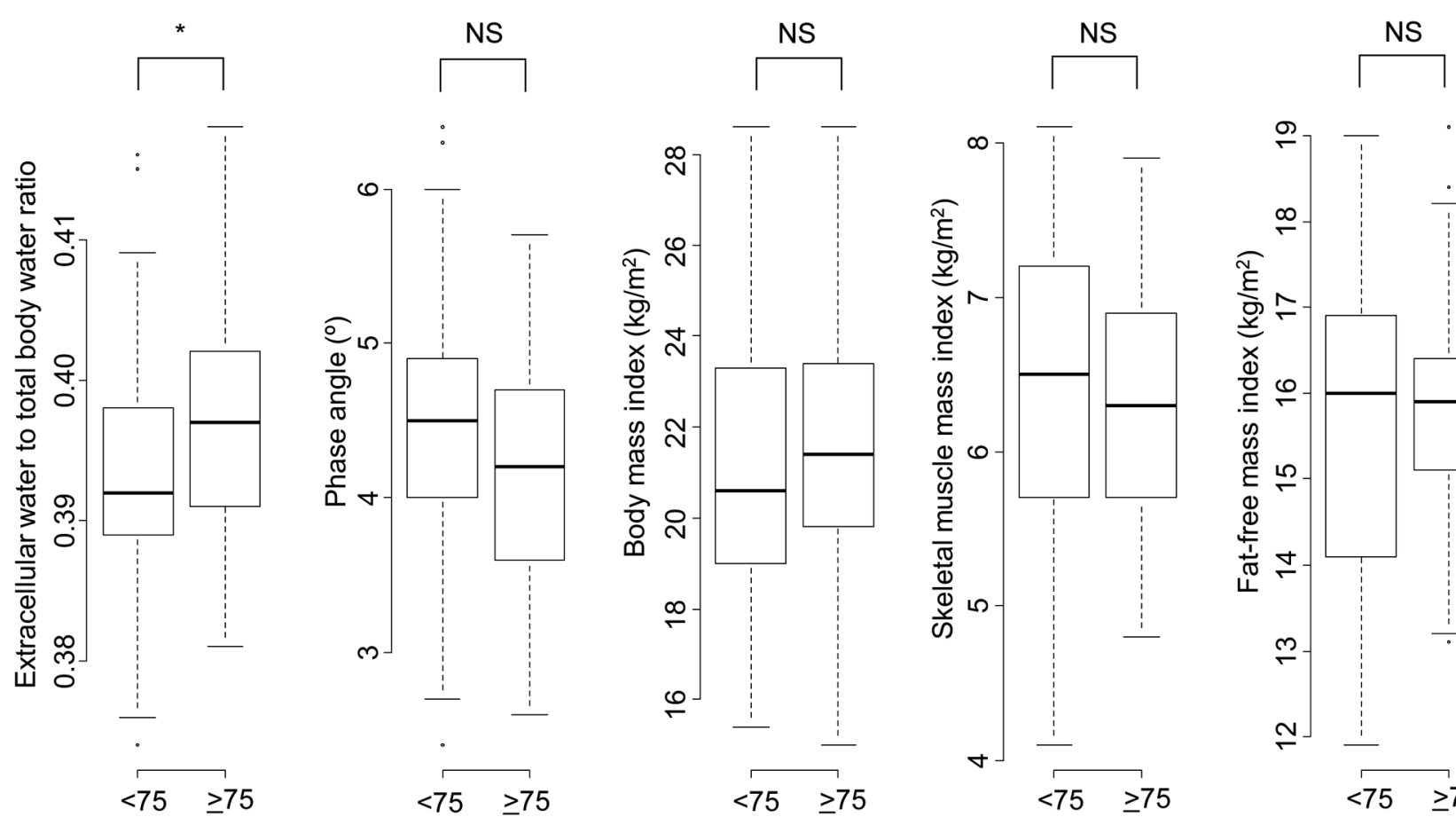

\section{Age (years old)}

Figure 2. Relationships between the bioelectrical impedance parameters and age. The ECW/TBW were significantly elevated in older patients $(\geq 75$ years, $\left.{ }^{*} p=0.027\right)$. The other BIA parameters were not correlated with age.
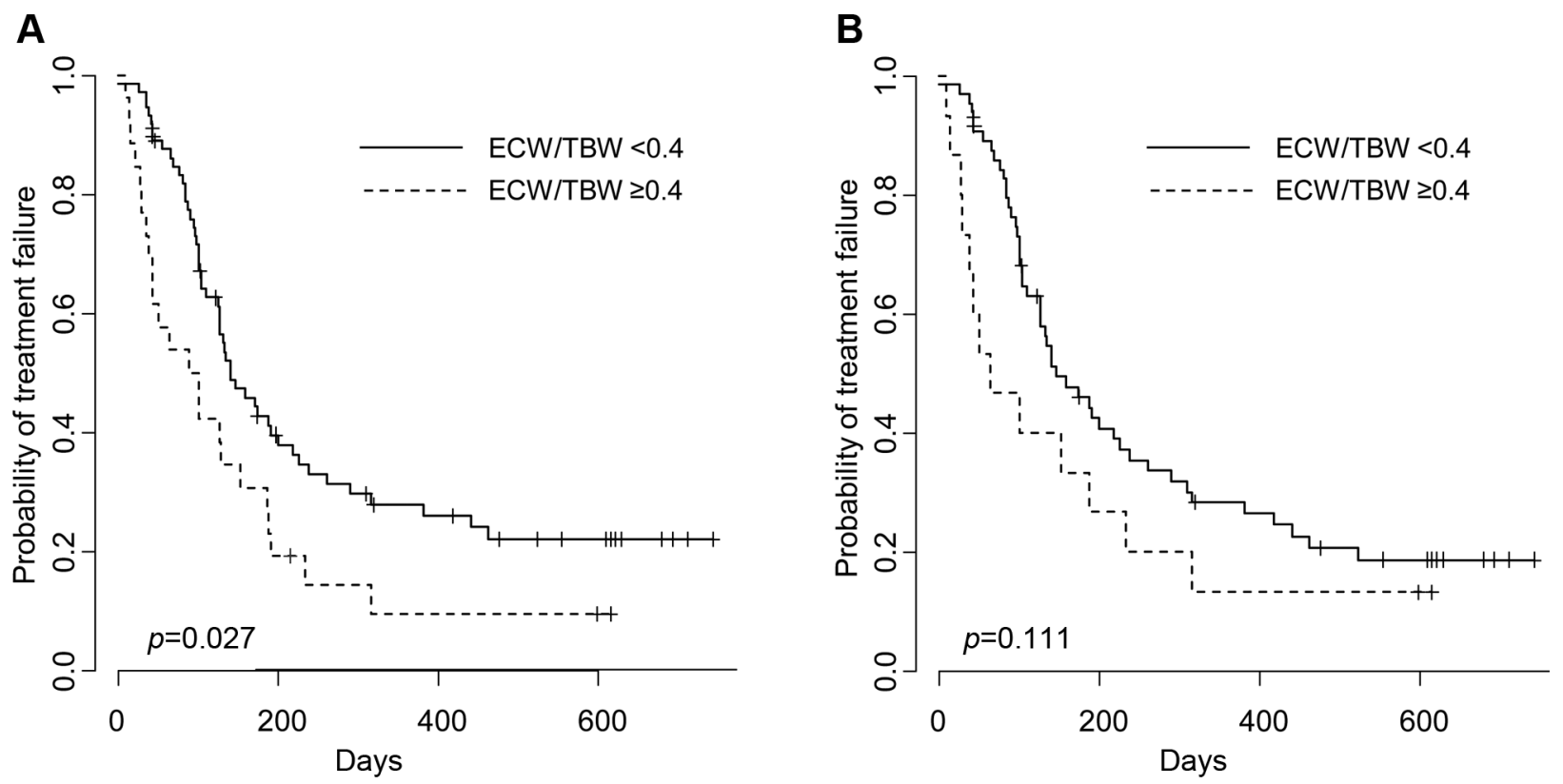

Figure 3. Kaplan-Meier plot of the time-to-treatment failure according to the extracellular water-to-total body water ratio. A: Patients in HG had significantly shorter median TTF (days) than those in LG (140 vs. 94, HR=1.74, 95\% CI=1.06-2.83; p=0.027). B: Patients with PS 0-1 in HG tended to have shorter median TTF (days) than those in LG (146 vs. 63, HR=1.64, 95\%CI=0.887-3.030; p=0.111). CI: Confidence interval; HG: higher group (ECW/TBW $\geq 0.4)$; HR: hazard ratio; LG: lower group (ECW/TBW <0.4); NA: not available; PS: performance status; TTF: time-to-treatment failure. 
Table III. Univariate and multivariate analysis of risk factors relating to TTF.

\begin{tabular}{|c|c|c|c|c|}
\hline \multirow[t]{2}{*}{ Variables } & \multicolumn{2}{|c|}{ Univariate analysis } & \multicolumn{2}{|c|}{ Multivariate analysis } \\
\hline & HR (95\%CI) & $p$-Value & HR (95\%CI) & $p$-Value \\
\hline Gender (Male) & $1.66(1.02-2.71)$ & 0.043 & $1.57(0.93-2.67)$ & 0.086 \\
\hline Age $\geq 75$ years & $1.09(0.69-1.71)$ & 0.718 & & \\
\hline Current or former smoker & $1.27(0.77-2.11)$ & 0.347 & & \\
\hline ECOG PS 2-3 & $1.90(1.08-3.37)$ & 0.027 & $1.51(0.79-2.88)$ & 0.219 \\
\hline Non-small cell lung cancer & $0.73(0.38-1.40)$ & 0.340 & & \\
\hline Stage IV or relapse & $0.94(0.53-1.65)$ & 0.828 & & \\
\hline Driver mutation positive & $0.48(0.26-0.89)$ & 0.019 & & \\
\hline Comorbidity $\geq 1$ & $1.45(0.90-2.31)$ & 0.124 & & \\
\hline Previous treatment line $\geq 1$ & $1.62(1.03-2.56)$ & 0.037 & $1.60(0.99-2.60)$ & 0.059 \\
\hline $\mathrm{ECW} / \mathrm{TBW} \geq 0.4$ & $1.74(1.06-2.83)$ & 0.027 & $1.80(1.03-3.14)$ & 0.045 \\
\hline Body mass index: low & $1.21(0.77-1.89)$ & 0.411 & & \\
\hline Skeletal muscle index: low & $1.30(0.82-2.06)$ & 0.257 & & \\
\hline Fat free muscle index: low & $1.38(0.85-2.24)$ & 0.188 & & \\
\hline C-reactive protein $(\mathrm{mg} / \mathrm{dl}) \leq 0.3$ & $1.54(0.98-2.42)$ & 0.062 & & \\
\hline Serum albumin $(\mathrm{g} / \mathrm{dl}) \leq 4.0$ & $0.52(0.32-0.84)$ & 0.007 & & \\
\hline Ratio of neutrophil to lymphocyte $\leq 3.1$ & $1.49(0.95-2.34)$ & 0.084 & & \\
\hline
\end{tabular}

CI: Confidence interval; ECOG PS: Eastern Cooperative Oncology Group performance status; ECW/TBW: extracellular water-to-total body water ratio; HR: hazard ratio; TTF: time-to-treatment failure.

(Osaka, Japan), Lilly Japan Co. Ltd. (Hyogo, Japan), AstraZeneca Co. Ltd. (Osaka, Japan), Taiho Pharmaceutical Co. Ltd. (Tokyo, Japan), Chugai Pharmaceutical Co. Ltd. (Tokyo, Japan), and MSD Oncology Co. Ltd. (Tokyo, Japan). T.H. did not receive honoraria and research funding associated with this study. The other Authors have no conflicts of interest to declare in relation to this study.

\section{Authors' Contributions}

All Authors were involved in the conception and design of this study, the acquisition of data, or the analysis and interpretation of data; drafting the article or revising it critically, and final approval of the version to be submitted. N.R., K.I., and Y.O. measured patients' BIA parameters with BIA scanners. N. R., K. I., Y.O., Y.N., and T.H. collected BIA data. T.H., Y.N, H.S., S.N., A.T, N.M., and N.O. collected clinical data. T.H., Y.N., H.S., and N.O. performed the statistical analyses.

\section{Acknowledgements}

The Authors wish to thank the patients and their families. The authors also extend their appreciation to Ms. Yuko Tani, who is their secretary, and who summarized the data. Finally, the Authors thank Editage (www.editage.jp) for English language editing.

\section{References}

1 Cancer Information Service, Cancer Registry and Statistics, National Cancer Center, Japan., Cancer Statistics in Japan. Available at: https://ganjoho.jp/reg_stat/statistics/dl/index.html\# incidence4pref [Last accessed on December 30, 2019]
2 Ethun CG, Bilen MA, Jani AB, Maithel SK, Ogan K and Master VA: Frailty and cancer: Implications for oncology surgery, medical oncology, and radiation oncology. CA Cancer J Clin 67(5): $362-$ 377, 2017. PMID: 28731537. DOI: 10.3322/caac.21406

3 Noda Y, Suzuki H, Kanai T, Samejima Y, Nasu S, Tanaka A, Morishita N, Okamoto N and Hirashima T: The association between extracellular water-to-total body water ratio and therapeutic durability for advanced lung cancer. Anticancer Res 40(7): 39313937, 2020. PMID: 32620634. DOI: 10.21873/anticanres.14384

4 Hara N, Iwasa M, Iwata K, Miyachi H, Tanaka H, Takeo M, Fujita N, Kobayashi Y and Takei Y: Value of the extracellular water ratio for assessment of cirrhotic patients with and without ascites. Hepatol Res 39(11): 1072-1079, 2009. PMID: 19619257. DOI: $10.1111 /$ j.1872-034X.2009.00546.x

5 Nongnuch A, Campbell N, Stern E, El-Kateb S, Fuentes L and Davenport A: Increased postdialysis systolic blood pressure is associated with extracellular overhydration in hemodialysis outpatients. Kidney Int 87(2): 452-457, 2015. PMID: 25075771. DOI: $10.1038 / \mathrm{ki} .2014 .276$

6 Park CS, Lee SE, Cho HJ, Kim YJ, Kang HJ, Oh BH and Lee HY: Body fluid status assessment by bio-impedance analysis in patients presenting to the emergency department with dyspnea. Korean J Intern Med 33(5): 911-921, 2018. PMID: 29241303. DOI: $10.3904 / \mathrm{kjim} .2016 .358$

7 Foster KR and Lukaski HC: Whole-body impedance - what does it measure? Am J Clin Nutr 64(3 Suppl): 388S-396S, 1996. PMID: 8780354. DOI: 10.1093/ajen/64.3.388S

8 Cha K, Chertow GM, Gonzalez J, Lazarus JM and Wilmore DW: Multifrequency bioelectrical impedance estimates the distribution of body water. J Appl Physiol (1985) 79(4): 13161319, 1995. PMID: 8567578. DOI: 10.1152/jappl.1995. 79.4 .1316 
9 Lukaski HC, Bolonchuk WW, Hall CB and Siders WA: Validation of tetrapolar bioelectrical impedance method to assess human body composition. J Appl Physiol (1985) 60(4): 1327-1332, 1986. PMID: 3700310. DOI: 10.1152/jappl.1986.60.4.1327

10 Cederholm T, Bosaeus I, Barazzoni R, Bauer J, Van Gossum A, Klek S, Muscaritoli M, Nyulasi I, Ockenga J, Schneider SM, de van der Schueren MA and Singer P: Diagnostic criteria for malnutrition - an espen consensus statement. Clin Nutr 34(3): 335340, 2015. PMID: 25799486. DOI: 10.1016/j.clnu.2015.03.001

11 Chen LK, Woo J, Assantachai P, Auyeung TW, Chou MY, Iijima K, Jang HC, Kang L, Kim M, Kim S, Kojima T, Kuzuya M, Lee JSW, Lee SY, Lee WJ, Lee Y, Liang CK, Lim JY, Lim WS, Peng LN, Sugimoto K, Tanaka T, Won CW, Yamada M, Zhang T, Akishita $\mathrm{M}$ and Arai $\mathrm{H}$ : Asian working group for sarcopenia: 2019 consensus update on sarcopenia diagnosis and treatment. J Am Med Dir Assoc 21(3): 300-307 e302, 2020. PMID: 32033882. DOI: 10.1016/j.jamda.2019.12.012

12 Guo Q, Yi C, Li J, Wu X, Yang X and Yu X: Prevalence and risk factors of fluid overload in southern chinese continuous ambulatory peritoneal dialysis patients. PLoS One 8(1): e53294, 2013. PMID: 23341936. DOI: 10.1371/journal.pone.0053294

13 R.C. Team, The R Project for Statistical Computing. Available at: https://www.r-project.org/ (Last accessed on December 31, 2020)

14 Huisingh-Scheetz M and Walston J: How should older adults with cancer be evaluated for frailty? J Geriatr Oncol 8(1): 8-15, 2017. PMID: 27318797. DOI: 10.1016/j.jgo.2016.06.003

15 Morley JE, Vellas B, van Kan GA, Anker SD, Bauer JM, Bernabei R, Cesari M, Chumlea WC, Doehner W, Evans J, Fried LP, Guralnik JM, Katz PR, Malmstrom TK, McCarter RJ, Gutierrez Robledo LM, Rockwood K, von Haehling S, Vandewoude MF and Walston J: Frailty consensus: A call to action. J Am Med Dir Assoc 14(6): 392-397, 2013. PMID: 23764209. DOI: 10.1016/j.jamda.2013.03.022

16 Cruz-Jentoft AJ, Baeyens JP, Bauer JM, Boirie Y, Cederholm T, Landi F, Martin FC, Michel JP, Rolland Y, Schneider SM, Topinkova E, Vandewoude M, Zamboni M and European Working Group on Sarcopenia in Older P: Sarcopenia: European consensus on definition and diagnosis: Report of the european working group on sarcopenia in older people. Age Ageing 39(4): 412-423, 2010. PMID: 20392703. DOI: 10.1093/ageing/afq034
17 Hilal Z, Rezniczek GA, Klenke R, Dogan A and Tempfer CB: Nutritional status, cachexia, and anorexia in women with peritoneal metastasis and intraperitoneal chemotherapy: A longitudinal analysis. J Gynecol Oncol 28(6): e80, 2017. PMID: 29027398. DOI: 10.3802/jgo.2017.28.e80

18 Miura T, Matsumoto Y, Kawaguchi T, Masuda Y, Okizaki A, Koga $\mathrm{H}$, Tagami K, Watanabe YS, Uehara Y, Yamaguchi T and Morita $\mathrm{T}$ : Low phase angle is correlated with worse general condition in patients with advanced cancer. Nutr Cancer 71(1): 83-88, 2019. PMID: 30686055. DOI: 10.1080/01635581.2018.1557216

19 Aleixo GFP, Shachar SS, Nyrop KA, Muss HB, Battaglini CL and Williams GR: Bioelectrical impedance analysis for the assessment of sarcopenia in patients with cancer: A systematic review. Oncologist 25(2): 170-182, 2020. PMID: 32043785. DOI: $10.1634 /$ theoncologist.2019-0600

20 Carrasco F, Carrasco Navarro GN, Rojas Moncada P, Papapietro $\mathrm{K}$ and Salazar G: Body composition assessment before and after weight loss following a Roux-en-Y gastric bypass. Are bioimpedanciometry estimations reliable? Nutr Hosp 37(6): 1150-1156, 2020. PMID: 33119392. DOI: 10.20960/NH.02942

21 Bell KE, Schmidt S, Pfeiffer A, Bos L, Earthman C, Russell C and Mourtzakis M: Bioelectrical impedance analysis overestimates fatfree mass in breast cancer patients undergoing treatment. Nutr Clin Pract 35(6): 1029-1040, 2020. PMID: 31769074. DOI: 10.1002/ ncp. 10438

Received January 15, 2021

Revised January 28, 2021

Accepted January 29, 2021 